Short Communication

\title{
Recovery of cellulose fibers from oil palm empty fruit bunch for pulp and paper using green delignification approach
}

\author{
Chung Loong Yiin ${ }^{\mathrm{a}}$, Syhui Ho ${ }^{\mathrm{b}}$, Suzana Yusup ${ }^{\mathrm{b}, *}$, Armando T. Quitain ${ }^{\mathrm{c}, \mathrm{d}}$, Yi Herng Chan ${ }^{\mathrm{b}}$, \\ Adrian Chun Minh Loy ${ }^{\mathrm{b}}$, Yong Ling Gwee ${ }^{\mathrm{b}}$ \\ ${ }^{a}$ Chemical Engineering Department, Faculty of Engineering, Computing and Science, Swinburne University of Technology, Jalan Simpang Tiga, Kuching, Sarawak 93350, \\ Malaysia \\ ${ }^{\mathrm{b}}$ Biomass Processing Cluster, HICOE-Centre for Biofuel and Biochemical Research, Institute of Self-Sustainable Building, Department of Chemical Engineering, Universiti \\ Teknologi PETRONAS, Seri Iskandar, Perak 32610, Malaysia \\ ${ }^{\mathrm{c}}$ Department of Applied Chemistry and Biochemistry, Faculty of Advanced Science and Technology, Kumamoto University, 2-39-1 Kurokami, Chuo-ku, Kumamoto 860- \\ 8555, Japan \\ ${ }^{\mathrm{d}}$ International Research Organization for Advanced Science and Technology, Kumamoto University, 2-39-1 Kurokami, Chuo-ku, Kumamoto 860-8555, Japan
}

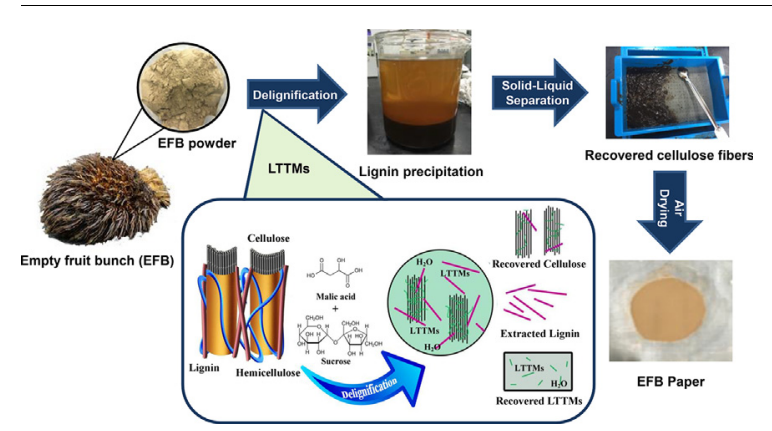

\section{A R T I C L E I N F O}

\section{Keywords:}

Oil palm empty fruit bunch

Low-transition-temperature-mixtures

Delignification

Fibers

Paper

\begin{abstract}
A B S T R A C T
The aim of this work was to recover the cellulose fibers from EFB using low-transition-temperature-mixtures (LTTMs) as a green delignification approach. The hydrogen bonding of LTTMs observed in ${ }^{1} \mathrm{H}$ NMR tends to disrupt the three-dimensional structure of lignin and further remove the lignin from EFB. Delignification process of EFB strands and EFB powder were performed using standard L-malic acid and cactus malic acid-LTTMs. The recovered cactus malic acid-LTTMs showed higher glucose concentration of $8.07 \mathrm{mg} / \mathrm{mL}$ than the recovered $\mathrm{L}$ malic acid LTTMs $(4.15 \mathrm{mg} / \mathrm{mL})$. This implies that cactus malic acid-LTTMs had higher delignification efficiency which led to higher amount of cellulose hydrolyzed into glucose. The cactus malic acid-LTTMs-delignified EFB was the most feasible fibers for making paper due to its lowest kappa number of 69.84. The LTTMs-delignified EFB has great potential to be used for making specialty papers in pulp and paper industry.
\end{abstract}

\section{Introduction}

The consumption for pulp and paper products is rising proportionally with the population growth in the world. Global paper demand is predicted to increase by an average of $2.1 \%$ per year (Suseno et al., 2017). Pulp and paper industry utilizes both hardwood and

\footnotetext{
* Corresponding author.

E-mail address: drsuzana_yusuf@utp.edu.my (S. Yusup).
} 